\title{
A Study on the Relationship between the Shareholding Ratio of the Controlling Shareholders and the Capital Occupation under the Different Capital Structures
}

\author{
Xuangang Lv \\ Beijing Normal University, Beijing, China \\ Email:1vxg1990@163.com
}

How to cite this paper: Lv, X.G. (2017) A Study on the Relationship between the Shareholding Ratio of the Controlling Shareholders and the Capital Occupation under the Different Capital Structures. American Journal of Industrial and Business Management, 7, 328-340.

https://doi.org/10.4236/ajibm.2017.73023

Received: March 6, 2017

Accepted: March 28, 2017

Published: March 31, 2017

Copyright $\odot 2017$ by author and Scientific Research Publishing Inc. This work is licensed under the Creative Commons Attribution International License (CC BY 4.0). http://creativecommons.org/licenses/by/4.0/

\section{Open Access}

\begin{abstract}
Based on Hansen's "threshold panel regression model" [1], this paper studies the relationship between shareholding ratio and capital occupation of listed companies in consideration of the difference of capital structure of the company, through the double threshold test method to determine the threshold value. The results show that there is a significant interval effect between the proportion of controlling shareholders and capital occupation of listed companies, but there is no "inverted U" relationship expected. The relationship between the two is due to the high ratio of assets to liabilities. And the "inverted U" relationship appears when the asset-liability ratio is low; the shareholding ratio of the controlling shareholder of the listed company is negatively correlated with the capital occupation, and when the asset-liability ratio is high, the two are positive related. We analyze the above-mentioned results from the cost and motivation of controlling shareholders of listed companies in China, and put forward some policy suggestions for listed companies, the main creditor banks and the regulators.
\end{abstract}

\section{Keywords}

Capital Structure, Controlling Shareholder, Capital Occupation, Panel Threshold Model

\section{Introduction}

In order to obtain the private benefits of control, the controlling shareholders often hollow out the company by means of direct occupation of the funds of the listed companies and transfer of the assets of the listed companies by connected transactions and loan guarantee by the listed companies [1]. The capital occupa- 
tion is even more prevalent in the listed companies in China. The capital occupation of the controlling shareholders directly encroaches on the cash flow necessary for the normal operation of the listed companies, which will inevitably adversely affect the company's operating performance. Other shareholders and the interests of creditors, destabilize the order of the entire financial market. The problem of capital occupation is not only originated from the company's ownership structure and internal governance mechanism, but also with regulators, banks which have great contact. Therefore, it is noteworthy that supervisors and banks work together to control and suppress the capital occupation of the controlling shareholders, to ensure the good operation of the listed companies, to protect the interests of minority shareholders and creditors, and to promote the healthy development of the market.

The controlling shareholder of the supervisory company has a direct influence on the behavior of capital occupation because of the larger control of the controlling shareholder and the ability to obtain the private gain of control. The effect of this kind of influence is decided by the fund occupation ability and the fund occupation motive. Under the joint action of the two, the controlling stakeholder's shareholding proportion and capital occupation will produce two kinds of different effects: "trench effect" and "synergistic effect". These effects play a direct role to determine the occupation behavior of the controlling shareholder. At the same time, the capital structure of listed companies will result in different risk distribution patterns; the shareholders and creditors for the company's regulatory motives and regulatory capacity are also quite different, and also affect the cost of controlling shareholder capital occupation. It is necessary to analyze the impact of controlling shareholder's proportion on capital occupation under the premise of considering different capital structures. Traditional subjective division of the listed companies based on the proportion of the controlling shareholder of the shareholding and capital structure of the classification often leads to regression of the larger errors; the accuracy is not high. Therefore, this paper uses Hansen's "threshold panel model" to automatically identify the data to determine the threshold, in order to make a scientific and accurate answer to this question.

The first part of this paper is the introduction; this part introduces the research background and significance. The second part is literature review, theoretical analysis and the research hypothesis; this part introduces and evaluates the existing problems at China and abroad research, based on principal-agent theory analysis and puts forward two hypotheses. The third part is the model set, using threshold regression model to study the research question. The fourth part is the empirical analysis, respectively, to test two hypotheses, and the test results are theoretical analysis. The fifth part is conclusion, to summarize the whole research.

\section{The Literature Review, Theoretical Analysis and Research Hypothesis}

\subsection{Literature Review}

There are two principal-agent problems in corporate governance, the first is the 
agency conflict between the owner (shareholder) and his agent (management); the second is between the majority shareholder and the majority shareholder of the proxy conflict. Ownership structure as an important institutional arrangement for corporate governance, when the company shares more dispersed, the majority of shareholders for regulatory costs are considered to be able to "free riders" to achieve the management of the company's supervision, which led to unattended management. And thus the management can easily obtain the private benefits of control without supervision pressure. The self-interest will inevitably harm the interests of the shareholders. At the same time, because each shareholder holds fewer shares, he cannot acquire the control right. Private benefit, the first type of agency problems highlighted. When the company's equity is more concentrated, the majority of the shareholders have more power because of the ownership of the management of the implementation of oversight, the majority of small shareholders choose to take major shareholders of the "car" to save their own regulatory costs, the company management in a large degree of attachment to the major shareholders, large shareholders have the ability through various means from the company for personal gain, the interests of minority shareholders, the second type of agency problems highlighted.

In developed countries, the equity of enterprises is generally dispersed, and the conflict of interest between shareholders and management is the main line of corporate governance [2], the first type of agency problem is more prominent. In the transition and emerging economies, the equity of the company is relatively concentrated, and the conflict of interest between large shareholders and small shareholders becomes the agent problem [3], the second kind of agency problem is relatively prominent. As an emerging economy, China's legal protection system for small and medium investors is not perfect. Therefore, the majority shareholder's occupation of medium and small shareholders is more serious. In particular, the problem of capital occupation by controlling shareholders is more common in Chinese listed companies.

Foreign scholars have long been concerned about the capital occupation of listed companies and conducted in-depth research [4] that the controlling shareholder through the "tunneling" (Tunneling) means to seek private benefits of control, the study also shows that holding Shareholders "tunneling" behavior is one of the causes of the 1997 Asian financial crisis. Bertrand pointed out that "hollowing out" behavior will reduce the transparency and reliability of accounting information, external investors, it is difficult to evaluate the financial situation of enterprises. [5] demonstrated the global prevalence of "hollowing out" behavior by large shareholders through empirical studies in 39 countries and regions. The research of the above three scholars mainly focused on the consequences of capital occupation, and did not discuss the mechanism of capital occupancy behavior, nor did it use quantitative research, [2] studied the listed companies according to the principal-agent theory, and put forward the "trench effect" and "synergistic effect" between the manager's shareholding ratio and firm's growth. Although Jensen et al. studied the relationship between the ratio 
of managerial ownership and the growth of the firm, and proposed the mechanism of the two effects on the principal-agent problem, it did not involve the controlling shareholder. For the second type of agency problems prominent transformation and the new economic countries, it is clear that the relationship between the controlling shareholder and the growth of the enterprise and whether the existence of these two effects is more worthy of attention.

In view of the existence of Chinese enterprises in the occupation of funds scholars and scholars have also conducted relevant research. They have analyzed the relationship between the ownership structure and the hollowing out behavior of the controlling shareholder through the analysis of the related transaction data. The results show that the listed company capital occupied by the controlling shareholder is the largest. There is a nonlinear relationship between the shareholding ratio and the share price [6]. Found that the first major shareholder of the tunnel effect and the trench effect, but there is no synergistic effect; enterprise group as a major shareholder tunneling, the effect is more obvious [7]. From the perspective of hollowing out the relationship between control and capital occupancy empirical analysis, found that the higher the proportion of controlling shareholders, listed companies in the smaller the size of capital occupied. Although the research of Li Zengquan and other scholars has explored the relationship between the proportion of controlling shareholders and the capital occupation by the quantitative method, the listed companies adopt artificial segmentation according to the proportion of the controlling shareholders. The results obtained are more general and less accurate. In terms of other related factors, [8] investigated the effect of different reforming models on the net capital occupation of listed companies after the issuance of the listed controlling shareholder and found that the controlling shareholder of the non-intact reforming company Prone to a net take-up of listed company funds. Other researchers discussed the conflict of interest between the major shareholder and the management from the background of China's system [9]. The study found that the occupation of funds would aggravate the conflict between the major shareholders and the management. The more capital occupied by the large shareholders, the greater the likelihood of change. These two studies have discussed the causes and consequences of capital occupation of listed companies from different perspectives. On the other hand, there are differences between the shareholders and the creditors in the regulation of business operation. On the other hand, there are differences between the shareholders and the creditors in the regulation of the business operation of the enterprises, while the capital structure plays an important regulatory role in the controlling shareholder's capital occupation. In addition, the banks as an important creditor of listed companies, the controlling shareholder of the occupation of funds will also affect their business conditions, thus affecting the stability of the entire financial market. However, the scholars do not introduce the capital structure as an important factor in the study of capital occupation, while ignoring the role of creditors, especially banks. Therefore, it is of theoretical and practical significance to study the relationship between 
shareholding ratio and capital occupation under different capital structure.

\subsection{Theoretical Analysis and Research Assumptions}

From the literature review can be seen, although the controlling shareholder and the relationship between the occupation of funds has been relatively rich, but the controlling shareholder of the shareholding ratio and capital occupancy in the end there is still no conclusive, and there is no literature on the two The relationship between the quantitative and accurate study. This paper holds that there is "trench effect" and "synergistic effect" between the controlling shareholder's shareholding proportion and the capital occupation, because when the controlling shareholder takes up the company's capital, it will inevitably affect the normal operation of the company and reduce the sharing of control rights. To a degree that would offset some of the private benefits of control acquired, which can also be regarded as the cost of capital occupied. For the controlling shareholder with lower shareholding, the loss of share of control is less than that of private use, and the motive of capital occupation increases with the increase of shareholding ratio. The "trench effect" shows that the shareholding proportion of the controlling shareholder With the increase of shareholding proportion of controlling shareholders, the losses caused by capital occupation to the value of the company will offset the more control private income of the controlling shareholder and the increase of occupation cost. The motive of capital occupation will be the proportion of holding shares is weakened, and the "synergy effect" shows that the proportion of controlling shareholders is negatively related to the capital occupation. There is a significant threshold between the threshold and the threshold. In different thresholds, there is a different relationship between the proportion of controlling shareholders and capital occupation. Based on this, this paper presents the first hypothesis:

Hypothesis 1:

The proportion of controlling shareholders is positively related to the capital occupation for the companies with less controlling shareholders. For the companies with a large proportion of controlling shareholders, the proportion of controlling shareholders is negatively related to the capital occupation.

Asset-liability ratio is an important index of the capital structure of listed companies. The ratio of shareholders' equity to total assets is small in the companies with high asset-liability ratio. The share value of controlling shareholders is relatively small. The loss of control benefit sharing is much less than the private benefit of control, and the cost of fund occupation is small. The motive will increase with the increase of shareholding ratio. The "trench effect" is obvious, meanwhile. The high risk of the enterprise, part of the business risk assigned to the creditors to bear the principal due to the principal interest and interest on the recovery of corporate regulatory power is not generally strong shareholders, which to some extent makes the issue of capital occupancy is more prominent. The ratio of shareholders' equity to total assets is higher in the companies with lower debt-to-asset ratio. The share value of the controlling shareholders in the 
total assets is correspondingly larger, and the share of the control rights in the capital occupancy behavior decreases. The co-effect is obvious, while for the low debt ratio of the enterprise, operating income of less than the proportion of private ownership, the proportion of private capital is higher than the growth of private benefits of control, the cost of capital occupied by the proceeds beyond the resulting, capital occupancy motives with the increase in the proportion of holding down. The risk is mainly borne by the shareholders, the shareholders of the strong regulatory power, to a certain extent, can also play a further role in the suppression of capital occupancy. There are also significant thresholds between the two models by threshold panel regression model. For the companies with different debt-to-asset ratio, there are different relations between the proportion of controlling shareholders and capital occupation. Based on this, this paper presents a second hypothesis.

Hypothesis 2:

For the companies with low asset-liability ratio, the proportion of controlling shareholders is positively related to the capital occupation. For the companies with high asset-liability ratio, the proportion of controlling shareholders is negatively related to the capital occupation.

\section{The Model Set}

According to the above theoretical analysis, the controlling shareholder's shareholding ratio and capital occupation may be non-linear because of the shareholding proportion and asset-liability ratio, and show the interval effect. In order to avoid artificially dividing the errors caused by asset-liability interval, this paper uses the threshold panel model developed by Hansen to divide the interval endogenously according to the characteristics of the data itself, and then study the relationship between shareholding proportion and capital occupation of different controlling shareholders. The single-threshold and double-threshold models are set as follows:

$$
\begin{gathered}
Y_{i t}=\mu_{i}+\theta x_{i t}+\beta_{1} \mathrm{~d}_{i t} I\left(g_{i t} \leq \gamma\right)+\beta_{2} \mathrm{~d}_{i t}\left(g_{i t}>\gamma\right)+\varepsilon_{i t} \\
Y_{i t}=\mu_{i}+\theta x_{i t}+\beta_{1} \mathrm{~d}_{i t} I\left(g_{i t} \leq \gamma_{1}\right)+\beta_{2} \mathrm{~d}_{i t} I\left(\gamma_{1}<g_{i t} \leq \gamma_{2}\right)+\beta_{3} \mathrm{~d}_{i t} I\left(g_{i t}>\gamma_{2}\right)+\varepsilon_{i t}
\end{gathered}
$$

where $i$ is the firm, $t$ is the year, and $Y_{i t}$ and $\mathrm{d}_{i t}$ are the explanatory variables (capital holdings) and the explanatory variables (the proportion of controlling shareholders) affected by the threshold variable. $X_{i t}$ is a set of control variables that have significant influence on capital occupation, including firm size, capital structure, size of board of supervisors, number of board meetings, percentage of independent directors and profitability, $g_{i t}$ is the threshold variable, in this paper, the controlling shareholders' $\Gamma$ is a specific threshold value, $\beta$ is a threshold variable, which explains the influence coefficient of the variable on the explanatory variable when the value range is different. $I(\cdot)$ is an indicator function. $M_{i}$ is used to reflect the individual effects of the firm, such as the unobservable factors such as corporate culture, $\varepsilon_{i t} \sim \operatorname{iid} N\left(0, \sigma_{2}\right)$ is the random interference term. 


\section{Empirical Analysis}

\subsection{Sample and Proxy Variables}

On this paper, we choose the A-share listed companies in Shanghai stock market from 2010 to 2014 as the research object. The following principles are adopted in the sample selection: 1) Deleting the listed companies in the financial industry; 2) Retaining 5 years in 2010-2014 related companies; 3) remove the sample interval is ST's company. Finally, 825 companies listed before Jan. 1, 2010 were selected as the research objects. The total number of samples was 4125 , and the data of all the listed companies were obtained from the CAMAR database.

Table 1 lists the proxy variable names and the definition methods in model (1) (2).

In the model, the explanatory variable is the capital occupation. The main means of capital occupation by the controlling shareholder is the related party transaction. The main performance of the financial statements is other receivables and payables. Therefore, this paper measures the extent of the use of funds on the use of other receivables and other payables the difference between the ratios of total assets. The core explanatory variable is the controlling shareholder's holding proportion, the control variable is: 1) represents the natural logarithm of the total assets of the company scale; 2 ) the asset-liability ratio can see the proportion of the owner's equity in the total assets; 3 ) the proportion of independent directors, the number of board meetings held; 4) the company's operating conditions with the net assets of the net profit margin (including the number of directors of the board of supervisors), the size of the board of supervisors. The proportion of controlling shareholders and asset-liability ratio will be added as a threshold variable to the regression model to test the interval effect of the core explanatory variables.

\subsection{Empirical Results}

The first step is to determine the number of thresholds, so as to determine the form of the model. We have the threshold parameters for the share and lev

Table 1. Variables and their definitions.

\begin{tabular}{|c|c|c|}
\hline $\begin{array}{l}\text { Variable } \\
\text { grouping }\end{array}$ & Variable name & Variable to explain \\
\hline $\begin{array}{l}\text { Dependent } \\
\text { variable }\end{array}$ & Occupy & $\begin{array}{c}\text { Funds of the controlling shareholder of listed companies, } \\
\text { occupy }=\text { (other receivables-other payables)/total assets }\end{array}$ \\
\hline $\begin{array}{l}\text { Independent } \\
\text { variable }\end{array}$ & Share & The first big shareholder's stake \\
\hline \multirow{6}{*}{ Control variable } & lev & The asset-liability ratio \\
\hline & Size & Company scale, $\ln$ (asset) \\
\hline & jsize & The size of the board of supervisors \\
\hline & inde & Ratio of independent directors \\
\hline & $\mathrm{bm}$ & The number of board meeting \\
\hline & roa & Net interest rates \\
\hline
\end{tabular}


model separately for single threshold and dual threshold regression, the F value obtained and the use of "Bootstrap" derived P values in Table 2 and Table 3. By observing the test results, we found that the single-threshold and double-threshold effects are very significant; the corresponding self-sampling $P$ values were significantly less than 0.01 . Based on the characteristics of the threshold regression, the double-threshold test results can reject the hypothesis that there is only a single threshold in the model, so the following analysis will be based on the double-threshold model.

The threshold estimates for the threshold parameters, share and lev, and the corresponding 95\% confidence intervals are shown in Table 4. Figure 1 and Figure 2, the threshold value of the likelihood ratio function diagram, a more intuitive and clear reflection of the two threshold parameters of the respective threshold and confidence interval composition. From the figure, we can see that the two thresholds are 36.16 and 54.51 respectively when the parameter is share and the two thresholds are 35.114 and 57.262 when the threshold parameter is lev. According to these thresholds, we can classify the listed companies listed in the sample according to the proportion of controlling shareholders as low shareholding (share $\leq 36.16)$, medium shareholding $(36.16<$ share $\leq 54.51)$ and high holding (lev $\leq 35.114)$, medium debt $(35.114<$ lev $\leq 57.262)$ and high debt (lev $>57.262$ ), which can be divided into three types according to different asset-liability ratio.

Table 2. Threshold effect test (threshold parameter lev).

\begin{tabular}{cccccc}
\hline & \multicolumn{5}{c}{ The threshold parameter (lev) } \\
\cline { 2 - 6 } & F value & P value & \multicolumn{3}{c}{ Critical value } \\
\cline { 2 - 6 } & & & $1 \%$ & $5 \%$ & $10 \%$ \\
\hline Single threshold test & $355.372^{* * *}$ & 0.000 & 27.890 & 7.675 & 4.754 \\
Double threshold test & $366.005^{* * *}$ & 0.000 & -163.798 & -201.654 & -224.159 \\
\hline
\end{tabular}

Table 3. Threshold effect test (threshold parameter share).

\begin{tabular}{cccccc}
\hline & & \multicolumn{3}{c}{ The threshold parameter (share 1) } \\
\cline { 2 - 6 } & F value & P value & \multicolumn{3}{c}{ Critical value } \\
\cline { 2 - 6 } & & & $1 \%$ & $5 \%$ & $10 \%$ \\
\hline Single threshold test & $20.199^{* * *}$ & 0.000 & 6.580 & 4.144 & 2.784 \\
Double threshold test & $53.292^{* * *}$ & 0.000 & -15.073 & -19.502 & -26.431 \\
\hline
\end{tabular}

(1) P values and critical values were obtained by repeated sampling 300 times using "bootstrap" on the variable significantly. $(2){ }^{* *},{ }^{* *},{ }^{*}$ indicate significance levels at $1 \%, 5 \%$ and $10 \%$, respectively.

Table 4. Threshold estimation results.

\begin{tabular}{lcccc}
\hline & \multicolumn{2}{c}{ The threshold parameter (share 1) } & \multicolumn{2}{c}{ The threshold parameter (lev) } \\
\cline { 2 - 5 } & Estimated value $95 \%$ confidence interval Estimated value 95\% confidence interval \\
\hline Threshold value $\gamma 1$ & 36.160 & {$[35.390,38.310]$} & 35.114 & {$[34.391,37.201]$} \\
Threshold value $\gamma 2$ & 54.510 & {$[25.660,59.720]$} & 57.262 & {$[55.417,57.429]$} \\
\hline
\end{tabular}



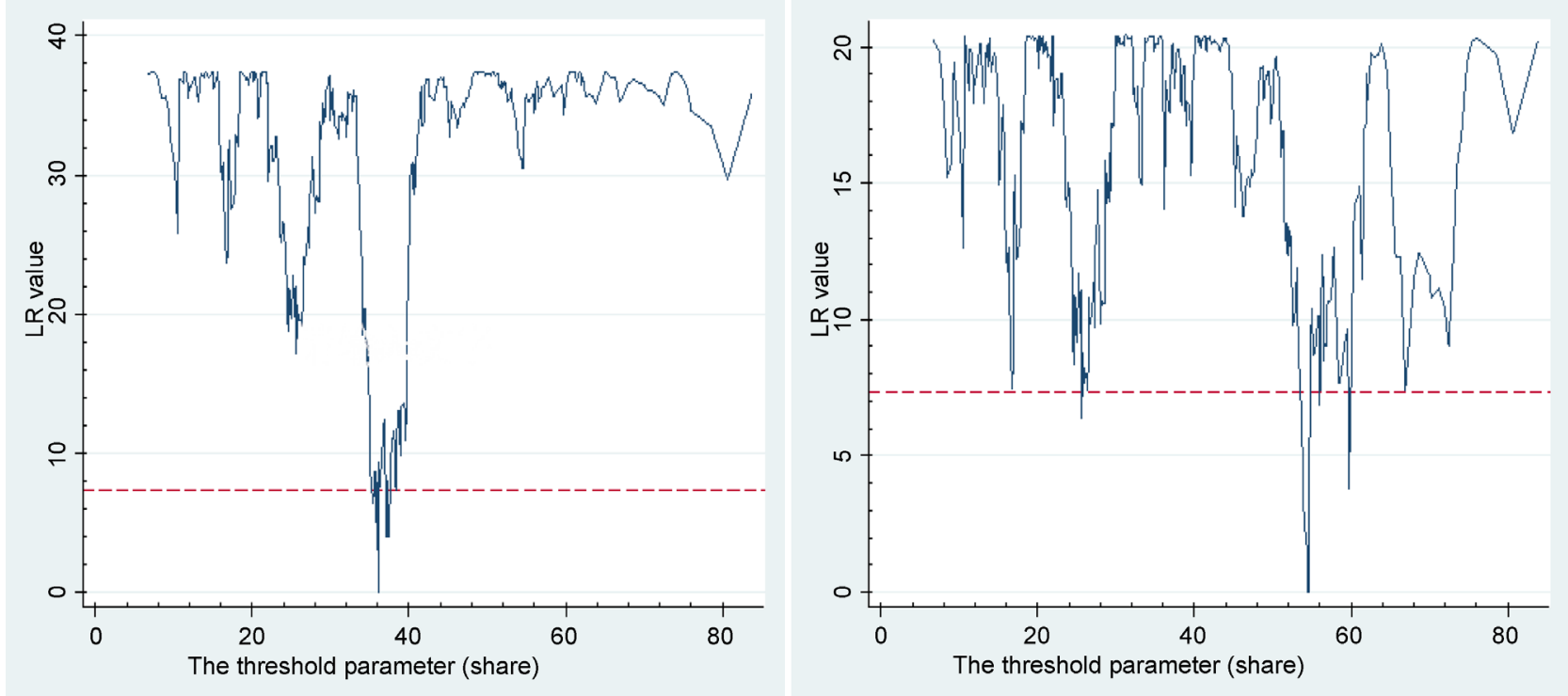

Figure 1. Threshold parameters for the controlling shareholder of the threshold ratio of stakeholder estimates and confidence intervals.
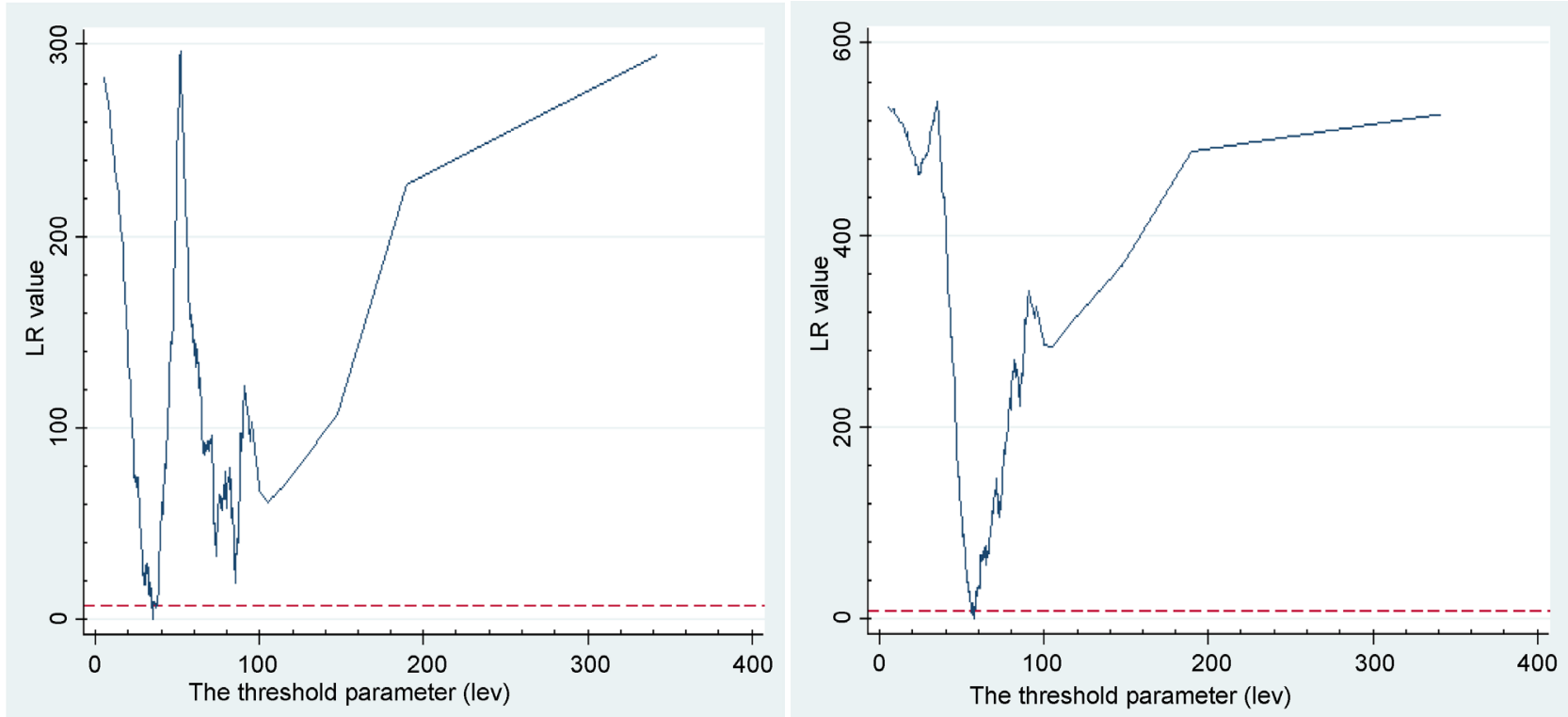

Figure 2. Threshold parameters for the asset-liability ratio of the threshold estimates and confidence intervals.

Table 5 shows the estimation results of the model parameters with the threshold parameters set as share and lev respectively. The key point of this paper is whether there is a threshold effect on the influence of the proportion of controlling shareholder on capital occupation. From the estimation results shown in Table 5, we can make a corresponding judgment on the hypothesis proposed in this paper.

Shareholding proportion of controlling shareholder, Table 5 shows that when the proportion of controlling shareholders is less than 36.16, the proportion of the controlling shareholders of the listed company has a significant positive effect on the capital occupancy, and the elasticity coefficient is 0.343 . When the 
Table 5. Parameter estimation results of the model.

\begin{tabular}{ccc}
\hline Variable & \multicolumn{2}{c}{ Coefficient estimates } \\
\hline \multirow{2}{*}{ Size } & The threshold parameter (share 1) & The threshold parameter (lev) \\
& $\left(16.343^{* * *}\right.$ & $2.189^{* * *}$ \\
lev & $-0.703^{* * *}$ & $(9.43)$ \\
& $(-101.22)$ & $-0.776^{* * *}$ \\
inde & $-0.0872^{*}$ & $(-115.38)$ \\
& $(-1.76)$ & -0.0374 \\
jsize & $3.169^{* * *}$ & $(-0.87)$ \\
& $(2.98)$ & $1.831^{*}$ \\
bm & $0.299^{* * *}$ & $(1.96)$ \\
& $(4.36)$ & $0.119^{* *}$ \\
roa & $-0.238^{* * *}$ & $(1.98)$ \\
& $(-9.38)$ & $-0.188^{* * *}$ \\
Share-1 & $0.343^{* * *}$ & $(-8.38)$ \\
& $(6.41)$ & $-0.499^{* * *}$ \\
Share-2 & $0.134^{* * *}$ & $(-21.61)$ \\
& $(4.03)$ & $-0.173^{* * *}$ \\
Share-3 & $0.0528^{* *}$ & $(-8.65)$ \\
& $(2.03)$ & $0.140^{* * *}$ \\
c & $-72.91^{* * *}$ & $(6.72)$ \\
& $(-12.31)$ & $-8.878^{\star}$ \\
R2 & 0.755 & $(-1.72)$ \\
\hline
\end{tabular}

When using share as the threshold value, the corresponding threshold interval is $(\gamma \leq 36.16,36.16 \leq \gamma \leq$ 54.51, $\gamma \leq 54.51)$. When using lev as the threshold value, the corresponding threshold interval is $(\gamma \leq$ $35.114,35.114<\gamma \leq 57.262, \gamma>57.262)$.

proportion of controlling shareholder is more than 36.16 and less than 54.51, the proportion of controlling shareholders has a positive effect on the capital occupation, but the elasticity coefficient decreases to 0.134 . When the proportion of controlling shareholder is more than 54.51, the proportion of controlling shareholders still has a positive effect on capital occupation, and the elasticity coefficient decreases again to 0.0528 . This indicates that the controlling shareholder's "synergistic effect" does not appear with the increase of the proportion of controlling shareholders, even when the controlling shareholder holds more than half of the total equity, the "trench effect" still exists. However, with the increasing proportion of controlling shareholders, the elasticity coefficient of capital occupancy has decreased obviously, and the "trench effect" has weakened. The "inverted U" relationship between shareholding ratio and capital occupancy is not shown in the previous hypothesis. This hypothesis is rejected.

Capital Structure. As shown in Table 5, when the asset-liability ratio is less than 35.114, the controlling shareholder's shareholding ratio of the listed company has a significant negative effect on the capital occupancy, and the elasticity coefficient is -0.499 . When the gearing ratio is greater than 35.114 and less than 57.262, the controlling shareholder's shareholding ratio has a significant negative effect on the capital occupation, but the effect is weakened, the elasticity coefficient is -0.173 . When the liability ratio is greater than 57.262 , the control- 
ling shareholder's shareholding ratio has a significant positive effect on the capital occupation, and the elasticity coefficient is 0.14 . This shows that when the ratio of assets and liabilities is low, with the controlling shareholder of listed companies to increase the proportion of holdings of controlling shareholders to take up funds were curbed, "synergies" shows that with the asset-liability ratio, "synergies" weakened, When the asset-liability ratio increased to a certain extent, the "trench effect" appears. This hypothesis is validated by the U-shaped relationship between asset-liability ratio and capital occupancy behavior of the controlling shareholder.

\subsection{The Results of Analysis}

\subsubsection{The Analysis of Hypothesis 1 Is Not Established}

We assume that with the increase in the proportion of controlling shareholders, the relationship between capital occupation and capital occupancy will change from positive to negative, from "trench effect" to "synergistic effect". In this paper, with the increase of the proportion of controlling shareholders, the "trench effect" of the controlling shareholder has always existed, though gradually weakened, but has not yet changed to "synergistic effect". This is because with the increase in the proportion of controlling shareholders, their control rights in listed companies will increase accordingly, and the ability to obtain private benefits of control will be enhanced. This is one of the conditions for the appearance of "trench effect". In theory, with the increase in the proportion of shareholding of controlling shareholders, the cost of capital occupation will be increased accordingly. However, when only the shareholding ratio is considered, the reduction of the share of the control share of the controlling shareholder, that is, the cost of the occupied capital has not completely offset the increase of the private control gains brought by the occupation of funds. At the same time, the controlling shareholder of the controlling shareholder increases the ability to take up the capacity to increase, after the measure of cost income still choose the funds to occupy, "synergies" does not appear. However, with the increase of the proportion of controlling shareholders, the cost of capital occupation increases. Although it has not completely offset the private control gains, also to a certain extent, inhibit the occurrence of capital occupancy behavior.

\subsubsection{The Analysis of Hypothesis 2 Is Established}

The hypothesis 1, we discuss the proportion of controlling shareholders and the relationship between the share of funds, the expected assumption is not established. However, the controlling shareholder's proportion only represents its proportion in the owner's equity of the company. The occupied assets come from the total assets of the company. Therefore, considering the change of asset-liability ratio will get more accurate results. In the high-liability companies, assetliability ratio is relatively high, the owner of equity is relatively small, the proportion of controlling shareholders holding a certain time, its shareholding value relative to the total assets of a smaller proportion of capital occupied by the loss of control rights sharing gains Small, controlling shareholder capital occupation 
cost is low, so get control of private income motivation strong. At the same time, most of the debts of listed companies come from bank loans, the main concern of the bank principal and interest recovery, did not participate in substantive decision-making, the lack of supervision of the controlling shareholder, which leads to a higher debt ratio of the larger companies, The low cost of private interest of the controlling shareholder, plus a part of the business risk to the creditor to bear, the corresponding increase in capital occupancy; the other hand, low-debt companies, asset-liability ratio is low, the owner's equity The shareholding proportion of the controlling shareholder is relatively large, the share value of the controlling shareholder is relatively larger than the total assets, the loss of the share of the share of control rights caused by capital occupation is large, and the controlling shareholder's capital occupying cost is high, thus obtaining private control Earnings motives are weak. At the same time, the ratio of assets and liabilities also determines the distribution of business risk, low-liability companies, business risky creditors to bear a smaller proportion of shareholders to bear a larger proportion of risk, taking into account the increase in capital occupancy behavior Operating risk, the controlling shareholder will tend to reduce the funds occupied behavior. In addition, the cost of capital occupied by the controlling shareholder is higher in the low-liability company, and the synergistic effect is stronger, and the synergetic effect appears. In the case of highly indebted companies, the "ditch effect" is reversed. Therefore, there is a range effect on the influence of the proportion of the controlling shareholder on the capital occupation. The capital structure of the controlling shareholder has a U-shaped relationship with the capital occupying behavior of the controlling shareholder, and the theoretical hypothesis is verified.

The results of this study are consistent with the results of previous studies, but the results are more accurate. Therefore, it has more practical significance, can also be used as a reference for the decision-making body.

\section{Conclusion}

This paper uses the panel data of A-share non-financial listed companies from 2010 to 2014 to study the relationship between shareholding proportion and capital occupation of different capital structures through the return of threshold. Although the "trench effect" weakened with the increase of the proportion of controlling shareholders, there was no "synergistic effect" as suggested in the research hypothesis, and "trench effect" of the listed companies' "controlling shareholders" shareholding ratio and capital occupancy, The proportion of controlling shareholders and capital occupied also did not show "inverted U” relationship. However, according to the asset-liability ratio of the threshold parameter, the sample is divided into three types of low-debt, medium-liability and high-liability companies. It is found that when the asset-liability ratio is high, the proportion of controlling shareholders and capital occupies a "trench effect". The "trench effect" weakened and the "synergistic effect" appeared between the debt ratio and the asset-liability ratio. It shows that for the high-liability compa- 
ny, the controlling shareholder's share value is smaller than the total assets of the listed company. The capital occupation cost is smaller; the risk of the company's operation is more by the creditor. The shareholder's risk is smaller; the controlling shareholder's capital occupancy behavior will be more serious. The opposite is true for highly indebted companies.

\section{References}

[1] Hansen, B.E. (2000) Sample Splitting and Threshold Eastimation. Econometrica, 68, 575-603. https://doi.org/10.1111/1468-0262.00124

[2] Jensen. M.C. and Meckling, W.H. (1976) Theory of the Firm: Managerial Behavior, Agency Costs and Ownership Structure. Journal of Financial Economic, 3, 305-360.

[3] Shleifer, A. and Vishny, R.A. (1997) A Survey of Corporate Governance. The Journal of Finance, 52, 737-783. https://doi.org/10.1111/j.1540-6261.1997.tb04820.x

[4] Johnson, S.R., La Porta, R., Lopez-de-Slanes, F. and Shleifer, A. (2000) Tunneling. American Economic Review, 90, 22-27. https://doi.org/10.1257/aer.90.2.22

[5] Dyck, A. and Zingales, L. (2004) Private Benefits of Control: An International Comparison. The Journal of Finance, 59, 537-600. https://doi.org/10.1111/j.1540-6261.2004.00642.x

[6] Li, Z.Q. and Sun, Z. (2004) Emptied and Ownership Arrangement-From Major Shareholders Capital Takes Up the Empirical Data of Listed Companies in China. Accounting Research, No. 12, 3-13.

[7] Tang, Q.Q. and Luo, D.L. (2005) Big Shareholders Tunneling and Counterweight: The Empirical Evidence from the Chinese Market. China Accounting Review, No. 1, 63-86.

[8] Deng, J.P. and Sun, Y. (2007) Restructuring Mode, Capital Takes Up with Corporate Performance. Chinese Industrial Economy, No. 1, 104-112.

[9] Liang, S.K. and Chen, D.H. (2015) Will Large Shareholders Infringe the Interests of Management? Finance Research, No. 3, 192-206.

Submit or recommend next manuscript to SCIRP and we will provide best service for you:

Accepting pre-submission inquiries through Email, Facebook, LinkedIn, Twitter, etc. A wide selection of journals (inclusive of 9 subjects, more than 200 journals)

Providing 24-hour high-quality service

User-friendly online submission system

Fair and swift peer-review system

Efficient typesetting and proofreading procedure

Display of the result of downloads and visits, as well as the number of cited articles

Maximum dissemination of your research work

Submit your manuscript at: http://papersubmission.scirp.org/

Or contact ajibm@scirp.org 